\title{
RELATO DE EXPERIÊNCIAS: PROJETO LEITURA DE OLHOS FECHADOS
}

\author{
Mônica dos Anjos Lacerda Pena ${ }^{1}$
}

\section{RESUMO}

O presente trabalho relata a experiência com o projeto Leitura de Olhos Fechados - a imagem traduzida em palavras -, cujo objetivo é permitir que deficientes visuais tenham acesso à cultura e informação, por meio de produtos culturais como livros e filmes, com base em recursos como a audiodescrição. A audiodescrição permite $\mathrm{o}$ acesso de pessoas com deficiência visual ao cinema, teatro e programas de televisão. É uma importante ferramenta de acessibilidade às pessoas que não podem enxergar. Aqui, estão presentes algumas considerações acerca da criação do projeto, das etapas de execução e dos resultados alcançados. Tem-se ainda uma breve descrição de como as ações do projeto conseguiram unir ensino, pesquisa e extensão.

Palavras-chave: Acessibilidade. Audiodescrição. Cultura. Deficientes visuais.

\section{PROJECT READING EYES CLOSED}

\section{ABSTRACT}

The present study reports the experience with the project Reading Blink - the image into words - whose goal is to enable visually impaired people have access to culture and information, through cultural products such as books

\footnotetext{
${ }^{1}$ Pós-Graduada em Gestão Pública Municipal pela UESB. Especialista em Gestão Estratégica da Comunicação. Graduada em Comunicação Social pela UESB. Idealizadora e coordenadora geral do projeto. E-mail: monicaalacerda@gmail.com
}

\begin{tabular}{l|l|l|l|l}
\hline Revista Extensão \& Cidadania & Vitória da Conquista & v. 1, n. 2 & p. 173-182 & jul/dez. 2013 \\
\hline
\end{tabular}


and films, from features like audio description. The audio description allows access to visually impaired people to the cinema, theater and television. It is an important tool for accessibility to people who cannot see. Here are present some considerations about the creation of the project, the stages of implementation and outcomes. There is also a brief description of how the project's actions have succeeded in combining teaching, research and extension.

Keywords: Accessibility. Audio description. Culture. Visually impaired.

\section{O DESPERTAR PARA UM PROJETO INOVADOR}

Que tal fechar os olhos só por um momento? Já parou para pensar em como seria o dia sem poder enxergar o brilho e a luminosidade do sol? Ou, quem sabe, não poder apreciar uma bela noite de lua cheia? Já imaginou se vestir, arrumar aqui e ali, e, ao final, não poder ver no espelho o resultado? E se fosse verdade? Se não houvesse como mudar isso? Pois então, essas são apenas algumas das barreiras que os deficientes visuais enfrentam diariamente.

Foi fechando os olhos por alguns instantes que eu abri meu coração e minha mente em busca de algo que tornasse a qualidade de vida dessas pessoas um pouco melhor, lhes proporcionando mais informação e cultura. Depois de algumas pesquisas na internet, descobri o recurso da audiodescrição, ainda novo no país e pouco conhecido, inclusive por profissionais e pesquisadores da área do audiovisual em Vitória da Conquista. A audiodescrição permite a inclusão de pessoas com deficiência visual em cinema, teatro e programas de televisão.

Daí surgiu o projeto Leitura de Olhos Fechados - a imagem traduzida em palavras -, cuja proposta é permitir que deficientes visuais, pessoas que fazem parte de uma parcela da população que se encontra excluída, tenham acesso a alguns produtos culturais como livros, por meio de audiobooks, e filmes, com a ajuda da audiodescrição. Outrossim, o projeto busca ainda fomentar as discussões acerca da acessibilidade e despertar nas pessoas, de modo geral, o desejo de promover ações que atendam a esta parte da população. 
Lembro-me como hoje da surpresa de alguns colegas de trabalho e de profissão ao terem conhecimento de um dos objetivos do projeto por mim idealizado: promover sessões de cinema em audiodescrição para os deficientes visuais. Mas o que era espanto se tornou admiração e, com isso, a ideia, que embora desafiadora nascera pequena, tomou dimensões maiores e contou com a colaboração de muita gente.

Pioneiro na Bahia, o projeto "Leitura de Olhos Fechados" concorreu, em 2009, a um edital de fomento à cultura do Banco do Nordeste, e foi aprovado. Sua primeira edição foi realizada pela Prefeitura Municipal de Vitória da Conquista, por meio da Secretaria de Cultura e Turismo, e pela Pró-Reitoria de Extensão e Assuntos Comunitários da Universidade Estadual do Sudoeste da Bahia (UESB), com o patrocínio do Governo Federal e Banco do Nordeste e BNDES, por meio do Programa BNB de Cultura.

As atividades do projeto tiveram, ainda, a contribuição e o apoio do Núcleo de Inclusão e Acessibilidade do Aluno Especial à Biblioteca (NIAAEB) e do Programa Janela Indiscreta, ambos da UESB. É importante destacar também a parceira da Associação Conquistense de Integração do Deficiente (ACIDE) de Vitória da Conquista.

\section{AS ETAPAS DE REALIZAÇÃO}

O projeto foi pensado com base em uma estratégia de ação dividida em três etapas distintas. A primeira trata-se da aquisição de audiobooks e de filmes em audiodescrição. Estes ficaram sob a responsabilidade da Secretaria Municipal de Cultura e Turismo e aqueles foram entregues à ACIDE de Vitória da Conquista, complementando o acervo da Associação.

Foram adquiridos cerca de 100 títulos de livros em áudio. A escolha teve como base sugestões de professores da ACIDE, além de frequentadores da Instituição, e o resultado foi a aquisição de livros como: Comer, Rezar e Amar, O Caçador de Pipas, 1822, Querido Jonh, Auto da Compadecida e clássicos da literatura infantil, a exemplo de Cinderela e Alice no país das maravilhas. 
Posteriormente, após a aquisição dos filmes em audiodescrição, doados pela Programadora Brasil, teve início a segunda etapa do projeto: sessões gratuitas de cinema com o recurso da audiodescrição. De dezembro de 2010 a abril de 2011 foram realizadas diversas exibições de filmes, de documentários à ficção, do drama à comédia. Nas ocasiões, pessoas se emocionaram ao compreender pela primeira vez o enredo de um filme sem o auxílio de um acompanhante. A audiodescrição propicia isso, mais liberdade e informação às pessoas que não podem enxergar.

As exibições aconteceram na ACIDE e em outros locais, a exemplo da UESB, do auditório do Serviço Social do Comércio (SESC) e do Colégio Modelo. Isso, porque essa etapa do projeto acabou ganhando um formato itinerante, permitindo, assim, uma integração do público-alvo das sessões - os deficientes visuais - com outras pessoas e ambientes.

Mas não é só! O projeto, que inovou e proporcionou a troca de conhecimentos, atraiu olhares de centenas de pessoas com sua terceira etapa: a realização do Seminário Leitura de Olhos Fechados, de 22 a 24 de março de 2011, no Teatro Glauber Rocha da Uesb, campus de Vitória da Conquista. Um evento em prol da acessibilidade e produção de conhecimentos. A programação incluiu conferência, mesas-redondas, debates, oficina e exibições de filmes diversos.

A proposta era fomentar as discussões acerca da acessibilidade de pessoas com deficiência visual, e, para isso, o evento contou com a participação de palestrantes do Rio de Janeiro, Fortaleza, Jequié e Ipiaú, que apresentaram experiências, pesquisas e desafios da área. Representantes da Associação Conquistense de Integração do Deficiente (ACIDE), de Vitória da Conquista, professores da rede pública e privada, profissionais de diversas áreas, estudantes e familiares de pessoas com deficiência visual compareceram ao Seminário.

\subsection{As temáticas abordadas no Seminário}

"Acessibilidade: arte, cultura e (in) formação" e "Socializando saberes e construindo conhecimento". Essas foram a duas grandes temáticas abordadas durante a realização do Seminário Leitura de 
Olhos Fechados. A primeira buscou suscitar discussões acerca da acessibilidade à produção cultural, provocando discussões sobre os desafios da tradução audiovisual para o teatro e cinema, seja ela gravada ou ao vivo. Já a segunda foi uma maneira encontrada para socializar relatos de experiências e ações que possibilitam minimizar a distância entre as pessoas com deficiência visual e a cultura, de modo a estabelecer conquistas na valorização da diversidade.

\subsection{Oficina sobre audiodescrição}

Um dos momentos mais esperados com a realização do Seminário Leitura de Olhos Fechados foi a concretização da oficina de Introdução à Técnica da Audiodescrição, que aconteceu nas tardes dos dias 23 e 24 de março, no Teatro Glauber Rocha da UESB. Ministrada por Graciela Pozzobon, atriz e audiodescritora, que veio diretamente do Rio de Janeiro para apresentar técnicas desse novo recurso, tão eficaz na promoção de acessibilidade ao deficiente visual, a oficina teve como proposta formar multiplicadores, ou melhor, semear nas pessoas o desejo de ser um multiplicador.

\subsection{Mas, afinal, o que é audiodescrição?}

A audiodescrição é um recurso de acessibilidade que permite às pessoas com deficiência visual assistir e entender melhor filmes, peças de teatro, programas de TV, exposições, mostras, musicais, óperas e outros, ouvindo o que normalmente é visto. É a arte de transformar aquilo que é visto no que é ouvido.

Conforme se lê em http:/ / www.audiodescricao.com/home.htm:

A audiodescrição é um recurso de tecnologia assistiva que permite a inclusão de pessoas com deficiência visual junto ao público de produtos audiovisuais. $O$ recurso consiste na tradução de imagens em palavras. É, portanto, também definido como um modo de tradução audiovisual intersemiótico, onde o 
signo visual é transposto para o signo verbal. Essa transposição caracteriza-se pela descrição objetiva de imagens que, paralelamente e em conjunto com as falas originais, permite a compreensão integral da narrativa audiovisual. Como o próprio nome diz, um conteúdo audiovisual é formado pelo som e pela imagem, que se completam. A audiodescrição vem então preencher uma lacuna para o público com deficiência visual $(\mathrm{O}$ QUE É audiodescrição (AD)?, 2011).

Lívia M. V. M. Motta, especialista em audiodescrição, ressalta que este recurso não atende somente às pessoas com deficiência visual, trata-se de:

Um instrumento de inclusão cultural que irá contribuir para a formação crítica e para a educação da pessoa com deficiência visual, preparando-a para o exercício pleno de sua cidadania. Além disso, os benefícios de tal recurso estendem-se, também, às pessoas com deficiência intelectual, pessoas idosas e pessoas com dislexia (MOTTA, 2008).

Desde seu surgimento, em 1975, até os dias atuais, surgiram diversas definições para audiodescrição. Em cada lugar foi necessário definir o termo no momento de normalizar esse sistema de comunicação. No Brasil, ocorreu o mesmo. Assim, a Portaria no 188 , publicada no começo de 2010, define audiodescrição como:

A narração, em língua portuguesa, integrada ao som original da obra audiovisual, contendo descrições de sons e elementos visuais e quaisquer informações adicionais que sejam relevantes para possibilitar a melhor compreensão desta por pessoas com deficiência visual e intelectual (BRASIL, 2010).

Depois de muitas conversas, ofícios, reuniões, portarias ministeriais e manifestações, a audiodescrição em nosso país passou a ser uma realidade. $\mathrm{O}$ recurso em questão começou a ser obrigatório por duas horas semanais, a partir do dia $1^{\circ}$ de julho de 2011 , nas emissoras de TV com sinal digital. 
Esta é a primeira iniciativa do gênero na América Latina. Até o momento, somente o SBT, a TV Globo e a MTV divulgaram quais os programas terão audiodescrição, visando o cumprimento da Portaria $\mathrm{n}^{\circ}$ 188, publicada em março de 2010, pelo Ministério das Comunicações. Esta Portaria estipulou para 2011 pelo menos duas horas de programas com audiodescrição por semana. Sabe-se que isso está longe de ser o ideal, mas já é o começo.

\section{AS CONQUISTAS DO PROJETO}

Muitas foram as conquistas do projeto e, talvez, a maior delas tenha sido o despertar das pessoas para algo novo, que já existe, mas que, tal como já foi dito anteriormente, ainda é pouco conhecido - a audiodescrição. Com base nesse recurso é possível promover não só mais informação e cultura às pessoas portadoras de deficiência visual, mas, sobretudo, independência e dignidade, fazendo com que alguns direitos e garantias constitucionais, tais como o direito à liberdade e ao lazer, ora negados (e/ou ignorados) aos deficientes visuais, sejam materializados.

Com o projeto foi possível:

- Montar um acervo de livros em áudio e também de filmes audiodescritos;

- Contribuir com a formação de público para o cinema, com a realização de mais de quinze exibições de filmes em audiodescrição, a exemplo de $O$ Corintiano, de Milton Amaral, e Carmem Miranda: bananas is my busines, de Helena Solberg. Vale ressaltar que, embora não estivesse previsto no projeto, novas exibições foram realizadas ao longo de 2011, dando continuidade ao trabalho;

- Realizar um Seminário com o objetivo de fomentar as discussões acerca da audiodescrição - o primeiro da Bahia. Houve mais de 100 inscritos; 
- Integrar videntes e não videntes tanto nas sessões de cinema quanto durante o Seminário;

- Promover uma oficina para formar multiplicadores desse recurso, introduzindo-os à técnica da audiodescrição. Cerca de quarenta pessoas concluíram a oficina;

- Levar o assunto às TVs, rádios, jornais impressos, blogs e sites diversos de Vitória da Conquista e região, por meio de entrevistas e reportagens;

- Compartilhar experiências e ações desenvolvidas em outros estados com a participação de palestrantes do Rio de Janeiro e Ceará;

- Permitir que representantes do Centro de Apoio Pedagógico de Ipiaú e da Associação Jequieense de Cegos participassem das atividades, haja vista ser este um projeto extensionista, não devendo ele, portanto, estar preso à Universidade ou à cidade de Vitória da Conquista.

- Contribuir para a formação extracurricular dos estudantes, já que a participação no Seminário gerou a emissão de certificados de extensão com até 25 horas.

\section{A RESPONSABILIDADE EM CONTINUAR}

De acordo com o Instituto Brasileiro de Geografia e Estatística (IBGE), a partir do Censo 2000, o Brasil possui cerca de 1,6 milhão de pessoas com algum grau de deficiência visual. Muitos dos quais não têm acesso à cultura e informação em geral. Talvez por esse motivo, ao final do projeto, no dia 28 de abril de 2011, na ACIDE, houve um emocionante encontro e desabafo por parte daqueles maiores beneficiados com a realização do "Leitura de Olhos Fechados", com direito a lágrimas, aplausos e muitos agradecimentos a toda a equipe que trabalhou no projeto e aos parceiros, sem os quais nada disso seria possível. $\mathrm{Na}$ ocasião, um pedido foi unânime entre as pessoas que conheceram e/ou participaram do projeto, especialmente aquelas portadoras de deficiência visual: que o "Leitura de Olhos Fechados" tenha continuidade. 
Logo, a consequência não poderia ser outra! A segunda edição do projeto foi escrita, concorreu a um novo edital em 2011 e já foi aprovada. Em breve, novas atividades do projeto serão promovidas e, desta vez, contará com a aquisição de equipamentos como uma impressora em braile e ainda com a realização de ações no campus da UESB de Jequié, haja vista sua importância para projetos extensionistas expandir não somente as informações, os trabalhos, os resultados, mas, sobretudo, a unidade de alcance.

\section{CONSIDERAÇÕES FINAIS}

Ensino, pesquisa e extensão. Esses são os pilares de uma Universidade de qualidade. Pensando nisso, o projeto Leitura de Olhos Fechados realizou ações convergentes com essas três áreas. Para alcançar a relação de ensino/aprendizagem, foi promovida uma oficina gratuita e aberta a toda a comunidade sobre a audiodescrição. A oficina teve como proposta ensinar as etapas de construção de um roteiro audiodescrito, eficaz na compreensão de um filme por uma pessoa com deficiência visual, além de formar multiplicadores deste recurso, ou seja, audiodescritores.

Conforme já dito anteriormente, o projeto Leitura de Olhos Fechados é inovador e pioneiro na Bahia. Uma de suas propostas é fomentar as discussões e, com isso, as pesquisas, ora incipientes no Brasil, acerca do recurso audiodescrição. Poucos são os grupos de pesquisa, artigos e livros brasileiros que tratam sobre o assunto, mas com o Seminário proposto, este que contou com a participação de importantes pesquisadores, já é possível notar avanços nessa área, um bom exemplo disso é a própria publicação deste relato.

Mas, ensino e pesquisa devem caminhar junto com a extensão, sempre. Por isso, o projeto visou, ainda, promover ações fora da Universidade, como as exibições de filmes em audiodescrição, que aconteceram em ambientes internos e externos à Instituição. Igualmente, foi possível vivenciar um intercâmbio de conhecimentos e experiências 
com a participação de palestrantes e representantes de entidades de outras cidades e estados.

Contudo, faz-se necessário, ainda, ressaltar a importância de uma universidade abraçar esta ideia e aderir a novas práticas de inclusão. A UESB é uma das poucas Instituições de Ensino Superior na Bahia a formar deficientes visuais. Atualmente, possui estudantes com esta limitação em cursos como Direito, Pedagogia, dentre outros. Destarte, permitir a realização de um projeto dessa magnitude, cujo objetivo principal é promover mais informação e cultura às pessoas que não podem enxergar, é mais que proporcionar conhecimento e acessibilidade, é romper com barreiras e preconceitos.

\section{Referências}

BRASIL. Ministério das Comunicações. Portaria $n^{\circ}$ 188, de 24 de março de 2010. Brasília, 2010. Disponível em: <http://www.mc.gov.br/ images/2011/6_Junho/portaria_188.pdf > . Acesso em: 8 ago. 2011.

INSTITUTO BRASILEIRO DE GEOGRAFIA E ESTATÍSTICA (IBGE). Censo Demográfico 2000. Disponível em:

<http://www.ibge.gov.br/home/presidencia/noticias/noticia_ visualiza.php?id_noticia $=438 \& i d \_p a g i n a=1>$. Acesso em: 8 de março de 2011.

MACHADO, Flávia. Demorou, mas os programas de TV com audiodescrição estão no ar! Postado em 22 nov. 2011. Disponível em: <http:// comaudiodescricao.blogspot.com/2011/07/demorou-mas-osprogramas-de-tv-com.html>. Acesso em: 26 jul. 2011.

MOTTA, Lívia; Maria V. M. Audiodescrição: entrevista com Lívia Motta. Inclusive - Inclusão e Cidadania, 2008. Disponível em: <http://www. inclusive.org.br/?p=705>. Acesso em: 13 jul. 2010.

O QUE é audiodescrição (AD)? Disponível em: <http://www. audiodescricao.com/home.htm>. Acesso em: 8 ago. 2011. 